\title{
Viewpoint \\ Transforming growth factor-beta and mutant p53 conspire to induce metastasis by antagonizing p63: a (ternary) complex affair
}

\author{
Jean-Christophe Marine ${ }^{1}$ and Geert Berx ${ }^{2}$
} 'Laboratory for Molecular Cancer Biology, VIB-UGent, Technologiepark, 927, B-9052 Ghent, Belgium
2Laboratory of Molecular and Cellular Oncology, Department for Molecular Biomedical Research, VIB-UGent, Technologiepark, 927, B-9052 Ghent,
Belgium

Corresponding author: Jean-Christophe Marine, chris.marine@dmbr.ugent.be

Published: 27 July 2009

This article is online at http://breast-cancer-research.com/content/11/4/304

(c) 2009 BioMed Central Ltd
Breast Cancer Research 2009, 11:304 (doi:10.1186/bcr2337)

the activity of p63, itself a transcription factor and a key regulator of stem cell fate in epithelial tissues. The effect is facilitated by Smads, downstream effectors of TGF $\beta$ which act as a scaffold allowing mutant p53 to inactivate p63 transcriptional activity, most likely by interfering with its recruitment to the promoter regions of its target genes. Crucially, the formation of the p63-containing ternary complex is dependent on the level of both TGF $\beta$ and oncogenic Ras signaling.

The study thus identifies p63 as one of the very few suppressors of metastasis known to date and uncovers an intricate mechanism that antagonizes metastasis in cancer cells in response to TGF $\beta$. But why cancer cells would employ such an elaborate mechanism to inactivate p63 remains unclear. p63-inactivating mutations or bi-allelic loss could indeed be selected for during tumor progression as a more efficient, and irreversible, means to lose p63 function. One possibility is that p63 function is required for the establishment of a secondary tumor once the cancer cells have migrated from the primary tumor to distant metastatic sites. Consistent with this possibility is the role of p63 as an important regulator of the proliferative potential of epithelial stem cells [9].

The data presented in the article by Adorno and colleagues [8] also suggest that TGF $\beta$ in cooperation with oncogenic Ras is a potent inducer of epithelial mesenchymal transition (EMT), a form of phenotypic and functional plasticity that is an integral process during development and that is recapitulated during malignant progression of epithelial tumors [10]. p63 opposes TGF $\beta$-induced EMT, and according to the proposed model, the p53 status appears to be an important determinant for EMT response upon TGF $\beta$ exposure. This exciting possibility demands to be tested further. 
Adorno and colleagues [8] show that Smads directly bind to p63 in cancer cells and that this complex allows the recruitment of mutant p53. A p63/Smad complex may therefore also exist in healthy epithelial cells. The existence and the relevance of such a complex should be further explored, especially in the context of embryonic development. Of note is a previous discovery by the same group that binding between the Smads and wild-type p53 is required for TGF $\beta$ signaling during mesoderm formation in Xenopus [11].

The authors also identify two key p63 targets that mediate its antimetastatic activity: Sharp1, a regulator of circadian oscillations, and Cyclin G2, a protein that promotes cell cycle arrest in response to DNA damage. However, the mechanisms by which these genes suppress metastasis remain to be elucidated. How a protein involved in circadian oscillations could function as an inhibitor of metastasis is not immediately clear.

Using a panel of 1,200 primary breast tumors and associated clinical data, the authors went on to clinically validate Sharp1 and Cyclin G2 as important prognostic tools for breast cancer metastasis. Provocatively, they propose that these two genes provide a minimal metastatic signature with which breast cancer patients can be stratified according to the metastatic propensity of their tumors. This is especially striking since neither gene has previously been identified in known gene expression signatures that predict breast cancer metastasis and poor disease-free survival [12]. Further support for this claim is eagerly awaited as these findings are putatively of tremendous value given that the current molecular profiling involves screening of multiple gene signatures (MammaPrint relies on 70 genes and recurrence score on 21 genes). It will also be interesting to further explore the prognostic value of these two genes in other tumor types, especially those of epithelial origin.

In addition to providing the molecular mechanistic insights and diagnostic leads, the study points to new therapy possibilities. Targeting the mutant p53-Smads-p63 ternary complex with small molecules that inhibit the Smads-p63 interaction and/or mutant p53 binding to the Smads-p63 complex may represent an option for therapeutic intervention. Since the authors also show that Ras-mediated CK1 $\delta / \varepsilon$ dependent phosphorylation of mutant p53 is required for the formation of this complex, inhibitors of this kinase could efficiently interfere with the metastatic process. Promisingly, such inhibitors are already in various clinical trials.

\section{Competing interests}

The authors declare that they have no competing interests.

\section{Acknowledgments}

J-CM and GB are supported by Geconcerteerde Onderzoek Aangelegenheden (University Ghent, Belgium), the Belgian Federation Against Cancer, and the Association for International Cancer Research (St. Andrews, Scotland).

\section{References}

1. Liu G, McDonnell TJ, Montes de Oca Luna R, Kapoor M, Mims B, El-Naggar AK, Lozano G: High metastatic potential in mice inheriting a targeted p53 missense mutation. Proc Natl Acad Sci U S A 2000, 97:4174-4179.

2. Lang GA, Iwakuma T, Suh YA, Liu G, Rao VA, Parant JM, Valentin-Vega YA, Terzian T, Caldwell LC, Strong LC, El-Naggar AK, Lozano G: Gain of function of a p53 hot spot mutation in a mouse model of Li-Fraumeni syndrome. Cell 2004, 119:861872.

3. Olive KP, Tuveson DA, Ruhe ZC, Yin B, Willis NA, Bronson RT, Crowley D, Jacks T: Mutant p53 gain of function in two mouse models of Li-Fraumeni syndrome. Cell 2004, 119:847-860.

4. Soussi T, Beroud C: Assessing TP53 status in human tumours to evaluate clinical outcome. Nat Rev Cancer 2001, 1:233-240.

5. Hingorani SR, Wang L, Multani AS, Combs C, Deramaudt TB, Hruban RH, Rustgi AK, Chang S, Tuveson DA: Trp53R172H and KrasG12D cooperate to promote chromosomal instability and widely metastatic pancreatic ductal adenocarcinoma in mice. Cancer Cell 2005, 7:469-483.

6. Padua D, Massagué J: Roles of TGFbeta in metastasis. Cell Res 2009, 19:89-102.

7. Oft M, Peli J, Rudaz C, Schwarz H, Beug H, Reichmann E: TGFbeta1 and Ha-Ras collaborate in modulating the phenotypic plasticity and invasiveness of epithelial tumor cells. Genes Dev 1996, 10:2462-2477.

8. Adorno M, Cordenonsi M, Montagner M, Dupont S, Wong C, Hann B, Solari A, Bobisse S, Rondina MB, Guzzardo V, Parenti AR, Rosato A, Bicciato S, Balmain A, Piccolo S: A Mutant-p53/ Smad complex opposes p63 to empower TGFbeta-induced metastasis. Ce// 2009, 137:87-98.

9. Senoo M, Pinto F, Crum CP, McKeon F: p63 is essential for the proliferative potential of stem cells in stratified epithelia. Cell 2007, 129:523-536.

10. Janda E, Lehmann K, Killisch I, Jechlinger M, Herzig M, Downward $J$, Beug $H$, Grunert S: Ras and TGF $\beta$ ? cooperatively regulate epithelial cell plasticity and metastasis: dissection of Ras signaling pathways. J Cell Biol 2002, 156:299-314.

11. Cordenonsi $M$, Dupont $S$, Maretto $S$, Insinga $A$, Imbriano $C$ Piccolo S: Links between tumor suppressors: p53 is required for TGF-beta gene responses by cooperating with Smads. Cell 2003, 113:301-314.

12. Fan C, Oh DS, Wessels L, Weigelt B, Nuyten DS, Nobel AB, van't Veer LJ, Perou CM: Concordance among gene-expression-based predictors for breast cancer. N Engl J Med 2006, 355:560-569. 